Supplementary Information

\title{
Regulating the Coordination Environment of Ruthenium Cluster Catalyst for Alkaline Hydrogen Evolution Reaction
}

Tong Liu, ${ }^{\text {a }}$ Wei Zhang,,${ }^{\text {b* }}$ Tao Chen, ${ }^{\text {a,d }}$ Dong Liu, ${ }^{\text {a }}$ Linlin Cao, ${ }^{a}$ Tao Ding, ${ }^{\text {a }}$ Xiaokang Liu, ${ }^{\mathrm{a}}$ Beibei Pang, ${ }^{\mathrm{a}}$ Sicong Wang, ${ }^{\mathrm{a}}$ Lan Wang, ${ }^{\mathrm{a}}$ Qiquan Luo, ${ }^{\mathrm{c}, *}$ and Tao Yao ${ }^{\mathrm{a}, *}$

${ }^{a}$ National Synchrotron Radiation Laboratory, University of Science and Technology of China, Hefei 230029, P.R. China.

${ }^{\mathrm{b}}$ School of Materials, Sun Yat-sen University, Guangzhou 510275, Guangdong, China. ${ }^{\mathrm{c}}$ Institutes of Physical Science and Information Technology, Anhui University, Hefei, 230601, China.

${ }^{\mathrm{d}}$ School of National Defense Science and Technology, Southwest University of Science and Technology, Mianyang 621010, China.

*The corresponding author.

E-mail: yaot@ustc.edu.cn; zhangw368@mail.sysu.edu.cn; qluo@ustc.edu.cn 


\section{Experimental details.}

Synthesis of $\mathrm{Ti}_{3} \mathrm{C}_{2} \mathbf{T}_{\mathbf{x}}$ MXene nanosheets. Added $1 \mathrm{~g}$ of LiF to $10 \mathrm{ml}$ of $9 \mathrm{M} \mathrm{HCl}$ and stired for 2 minutes to obtain the uniform etching solution, $1 \mathrm{~g}$ of $\mathrm{Ti}_{3} \mathrm{AlC}_{2} \mathrm{MAX}$ phase powder was slowly added into the solution under magnetic stirring. The solution was then kept at $40{ }^{\circ} \mathrm{C}$ with magnetic stirring in an oil bath for $48 \mathrm{~h}$. The mixture was transferred to a $50 \mathrm{~mL}$ centrifuge tube and washed it with deionized water several times until the $\mathrm{pH}$ of the supernatant is approximately 6 (measured with $\mathrm{pH}$ test paper). Each wash was performed by centrifuging at $4000 \mathrm{RCF}$ for $3 \mathrm{~min}$. The washed precipitate was then re-dispersed into $30 \mathrm{ml}$ deionized water, and the mixture was ultrasonicated for $2 \mathrm{~h}$ under the protection of ice bath and argon. Subsequently, the ultrasonic solution was centrifuged at $6000 \mathrm{RCF}$ for $30 \mathrm{~min}$. After the supernatant was poured out, the remaining few layers of Mxene nanosheets precipitated were collected and dried overnight in a $60^{\circ} \mathrm{C}$ vacuum oven. Finally, the uniform MXene powder was obtained by grinding.

Synthesis of $\mathbf{R u}-\mathbf{T i}_{3} \mathbf{C}_{2} \mathbf{T}_{\mathbf{x}} .50 \mathrm{mg}$ of $\mathrm{Ti}_{3} \mathrm{C}_{2} \mathrm{~T}_{\mathbf{x}}$ MXene was added to $40 \mathrm{~mL}$ of Ethanol solution (20 $\mathrm{ml} \mathrm{DI}$ water, $20 \mathrm{ml}$ alcohol) and magnetic stirring for $5 \mathrm{~min}$ followed by mild ultrasonication for 30 min to produce a stable $\mathrm{Ti}_{3} \mathrm{C}_{2} \mathrm{~T}_{\mathrm{x}}$ MXene dispersion. Subsequently, $10 \mathrm{~mL}$ of $0.1 \mathrm{mg} / \mathrm{mL} \mathrm{RuCl}{ }_{3} \cdot \mathrm{xH}_{2} \mathrm{O}$ solution were added into the $\mathrm{Ti}_{3} \mathrm{C}_{2} \mathrm{~T}_{\mathrm{x}}$ MXene suspension drop by drop. The mixture was magnetically stirred for $12 \mathrm{~h}$. The solution was then centrifuged and washed with deionized water, the solid residue was vacuum freeze-dried. Afterwards, the obtained powder was placed in a tube furnace and heated at $600^{\circ} \mathrm{C}$ (ramp rate: $5^{\circ} \mathrm{C} / \mathrm{min}$ ) for $2 \mathrm{~h}$ under $\mathrm{Ar}(30 \mathrm{sccm})$ atmosphere. The resultant catalyst was labelled as $\mathrm{Ru}-\mathrm{Ti}_{3} \mathrm{C}_{2} \mathrm{~T}_{\mathrm{x}} @ 600$. For comparison, $\mathrm{Ru}-\mathrm{Ti}_{3} \mathrm{C}_{2} \mathrm{~T}_{\mathrm{x}} @ 300$, $\mathrm{Ru}-\mathrm{Ti}_{3} \mathrm{C}_{2} \mathrm{~T}_{\mathrm{x}} @ 450$ and $\mathrm{Ru}-\mathrm{Ti}_{3} \mathrm{C}_{2} \mathrm{~T}_{\mathrm{x}} @ 750$ samples were prepared by only changing the heating temperature $\left(300^{\circ} \mathrm{C}, 450^{\circ} \mathrm{C}, 750^{\circ} \mathrm{C}\right)$.

\section{Characterizations.}

The concentration of Ru atoms was directly measured by ICP-OES (Optima 7300 DV, PerkinElmer). The field emission scanning electron microscopy (SEM) images was 
taken on a Gemini SEM 500 scanning electron microscope. The morphologies of the samples were examined by TEM on JEOL-2100F systems at an accelerating voltage of $200 \mathrm{kV}$. EDS elemental mapping were obtained on a 26FEI Talos F200X device at 200 $\mathrm{kV}$. XPS measurements were carried out on ESCALAB 250Xi instrument. The binding energy scale of all measurements was calibrated by referencing C $1 \mathrm{~s}$ to $284.6 \mathrm{eV}$.

\section{EXAFS experimental details.}

The Ru K-edge (22117 eV) XAFS spectra was measured at the 1W1B beamline of Beijing Synchrotron Radiation Facility (BSRF), China. The storage ring of BSRF was operated at $2.5 \mathrm{GeV}$ with a maximum electron current of $250 \mathrm{~mA}$. During XAFS measurements, we calibrated the position of the absorption edge $\left(\mathrm{E}_{0}\right)$ using Ru foil. And all the XAFS data were collected during one period of beam time. The position of $\mathrm{E}_{0}$ is defined as the point corresponding to the maximum value in the derivative curves of the XANES spectra.

\section{Electrochemical measurements.}

The electrochemical measurements were performed using a standard H-type threeelectrode cell equipped with an electrochemical workstation (Model CHI760E, CH instruments), which was used to record the electrocatalytic activity in an $\mathrm{N}_{2}$-saturated $1 \mathrm{M} \mathrm{KOH}$ solution at room temperature. Furthermore, the graphite rod was chosen as the counter electrode and $\mathrm{Hg} / \mathrm{HgO}$ was used as the reference electrode. Approximate 5 $\mathrm{mg}$ of the catalysts were ultrasonically dispersed in $1 \mathrm{~mL}$ of $3: 2$ (volume ratio) deionized water and isopropanol mix solvent with $25 \mu \mathrm{L}$ of Nafion solution ( $5 \mathrm{wt} \%$ ), then the homogeneous ink was pipetted out and dropped onto a carbon paper with an area of $1 * 1 \mathrm{~cm}^{2}$ and then fully dried at room temperature. The catalyst loading was calculated to be $\sim 1 \mathrm{mg}$. For comparison, commercial $20 \% \mathrm{Pt} / \mathrm{C}$ catalyst were also prepared by depositing the same mass loading of electrocatalyst on the carbon paper using an identical method. As for HER experiment, the potential was referenced to the reversible hydrogen electrode (RHE) according to the following equation $\left[\mathrm{E}_{\mathrm{RHE}}=\right.$ 
$\left.\mathrm{E}_{\mathrm{Hg} / \mathrm{HgO}}+0.0592 \mathrm{pH}+0.098 \mathrm{~V}\right]$. Electrochemical impedance spectroscopy measurements were tested by applying an AC voltage with $5 \mathrm{mV}$ amplitude in a frequency range from $100 \mathrm{KHz}$ to $100 \mathrm{mHz}$ at overpotential of $100 \mathrm{mV}$, respectively. $\mathrm{CV}$ ranging from 10 to $100 \mathrm{mV} \mathrm{s}^{-1}$ was conducted to calculate the double layer capacitance $\left(\mathrm{C}_{\mathrm{dl}}\right)$. To investigate the cycling stability, $\mathrm{CV}$ was performed at a scan rate of $100 \mathrm{mV} \mathrm{s}^{-1}$.

\section{DFT calculations.}

The calculations were performed within the Density Functional Theory (DFT) framework implanted in Vienna ab initio Simulation Package (VASP). ${ }^{1}$ The interaction between ions and electrons was described in the Projector Augmented Wave (PAW) Method. ${ }^{2}$ The electron exchange and correlation energy were described using the generalized gradient approximation-based Perdew-Burke-Erzenhorf (PBE) functional. ${ }^{3}$ The semi-empirical London dispersion corrections of Grimme and colleagues (DFT-D3) were conducted to calculate the interactions between absorbers and slabs. The models of Ru- $\mathrm{Ti}_{3} \mathrm{C}_{2} \mathrm{~T}_{\mathrm{x}} @ 300$ and $\mathrm{Ru}-\mathrm{Ti}_{3} \mathrm{C}_{2} \mathrm{~T}_{\mathrm{x}} @ 600$ with a $3 \times 3 \times 1$ supercell were chosen for the calculation. and all the atoms were fully relaxed during the calculations. The $\mathrm{Ru}(110)$ atomic model with a $2 \times 2 \times 1$ supercell was chosen to represent the structure of $\mathrm{Ru}_{-} \mathrm{Ti}_{3} \mathrm{C}_{2} \mathrm{~T}_{\mathrm{x}} @ 750$. A sufficiently large vacuum region of $15 \AA$ was used for all the models to ensure the periodic images were well separated. the Brillouin-zone integrations were carried out using Monkhorst-Pack grids of special points. A gamma-centered $(4 \times 4 \times 1)$ k-point grid was used for all the models. To obtain the accurate structure, The plane-wave cutoff energy was set up to $500 \mathrm{eV}$. The force convergence was set to be $<0.02 \mathrm{eV} \AA^{-1}$, and the total energy convergence was set to be $<10^{-5} \mathrm{eV}$. The free energy of the adsorbed state was calculated as follows based on the adsorption energy:

$$
\Delta \mathrm{G}_{\mathrm{H}^{*}}=\Delta \mathrm{E}_{\mathrm{H}^{*}}+\Delta \mathrm{E}_{\mathrm{ZPE}}+\mathrm{U}_{(\mathrm{T})}-\mathrm{T} \Delta \mathrm{S}
$$

where $\Delta \mathrm{E}_{\mathrm{H}^{*}}$ is the adsorption energy of hydrogen directly obtained from DFT calculations, $\Delta \mathrm{E}_{\mathrm{ZPE}}$ is the zero-point energy, $\mathrm{U}_{(\mathrm{T})}$ is the heat capacity correction energy, and $\mathrm{T}$ is the temperature $(\mathrm{T}=298.15 \mathrm{~K}), \Delta \mathrm{S}$ is the change in entropy. Herein, the Gibbs energy is corrected by using the VASPKIT code. ${ }^{4}$ 

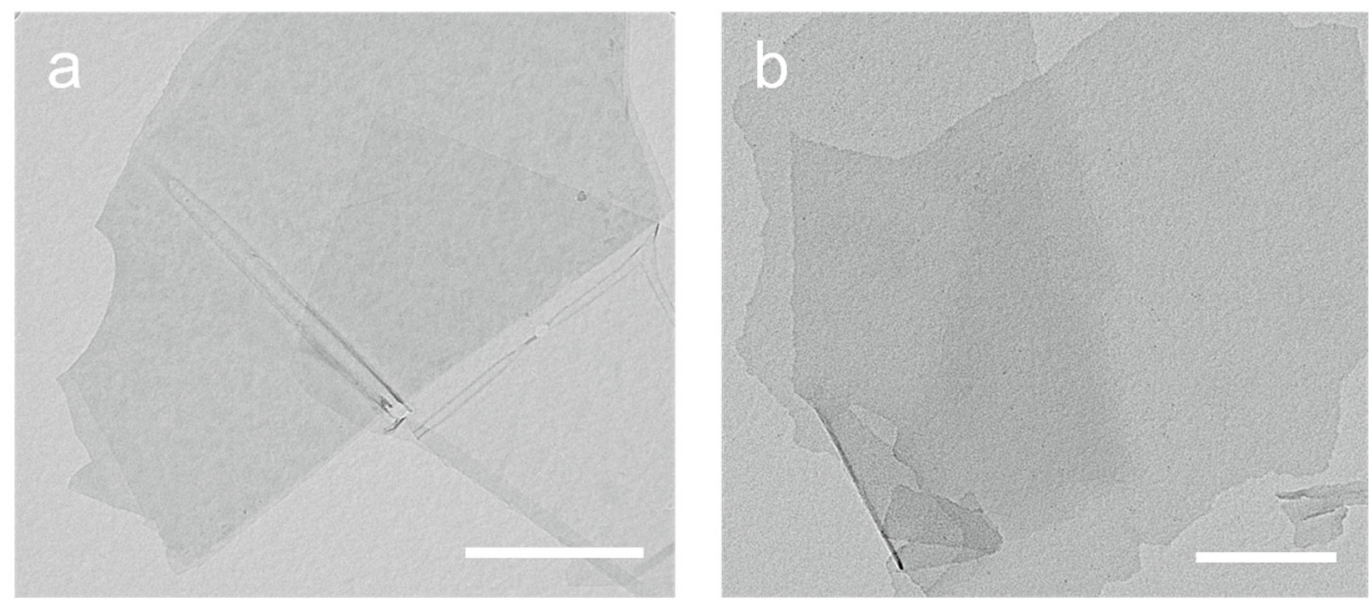

Figure S1. TEM image of few-layered $\mathrm{Ti}_{3} \mathrm{C}_{2} \mathrm{~T}_{\mathrm{x}}$, Scale bar, $500 \mathrm{~nm}$ in (a) and Scale bar, $200 \mathrm{~nm}$ in (b).
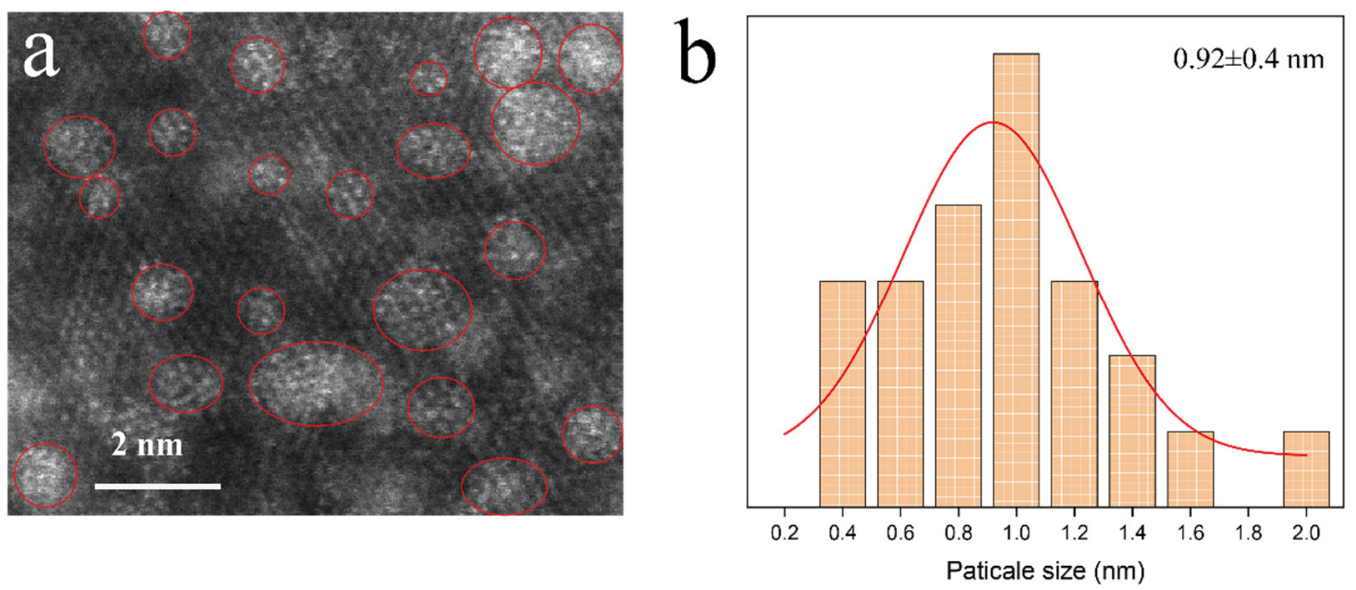

Figure S2. (a) HAADF-STEM image and (b) the size distribution curve of Ru$\mathrm{Ti}_{3} \mathrm{C}_{2} \mathrm{~T}_{\mathrm{x}} @ 600$ (bright dots marked with red circles indicate the Ru clusters on the $\mathrm{Ti}_{3} \mathrm{C}_{2} \mathrm{~T}_{\mathrm{x}}$ MXene support). 

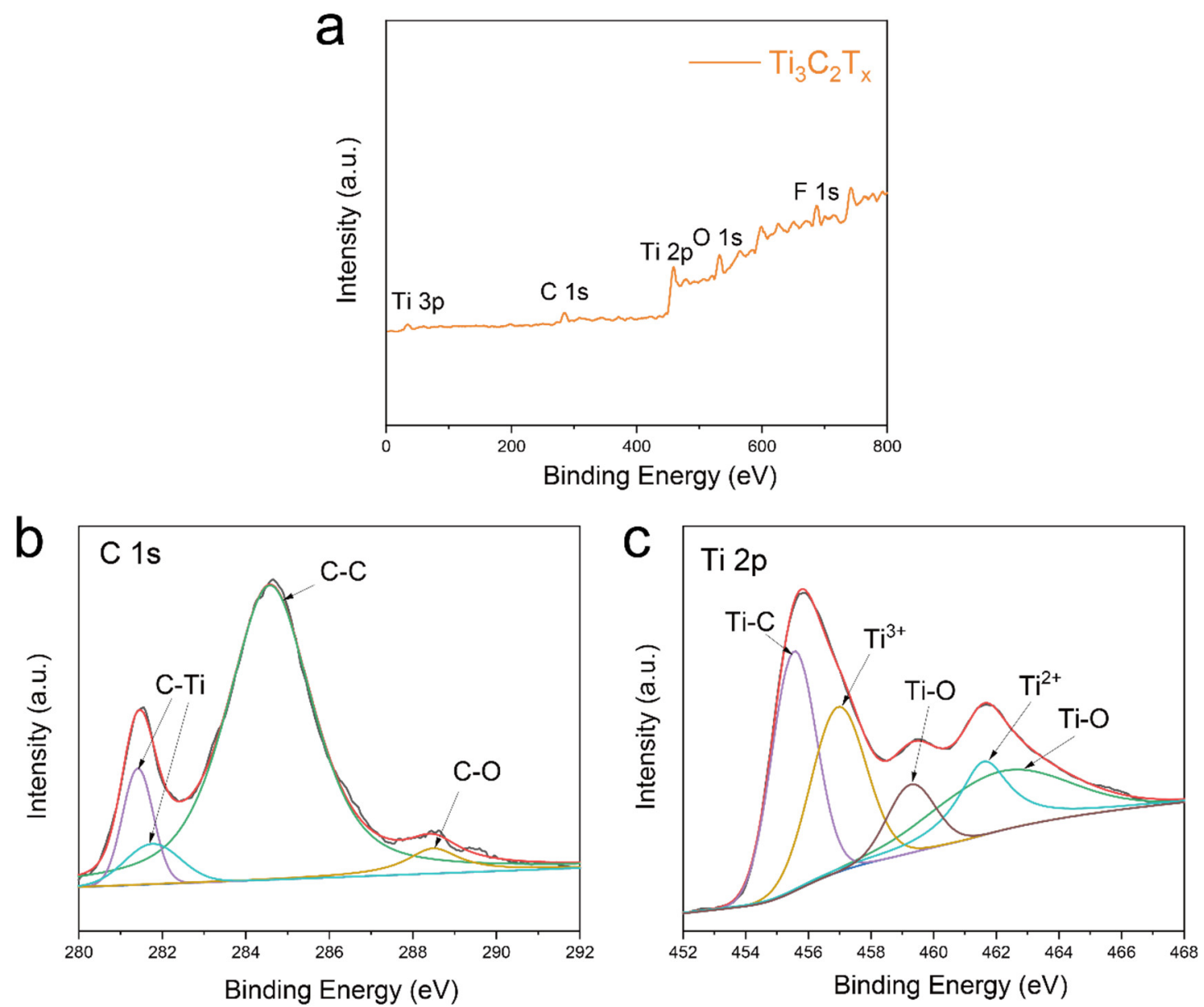

Figure S3. (a) Survey scan, (b) high resolution C 1s XPS spectra and (c) high resolution Ti $2 p$ XPS spectra of $\mathrm{Ti}_{3} \mathrm{C}_{2} \mathrm{~T}_{\mathrm{x}}$. 


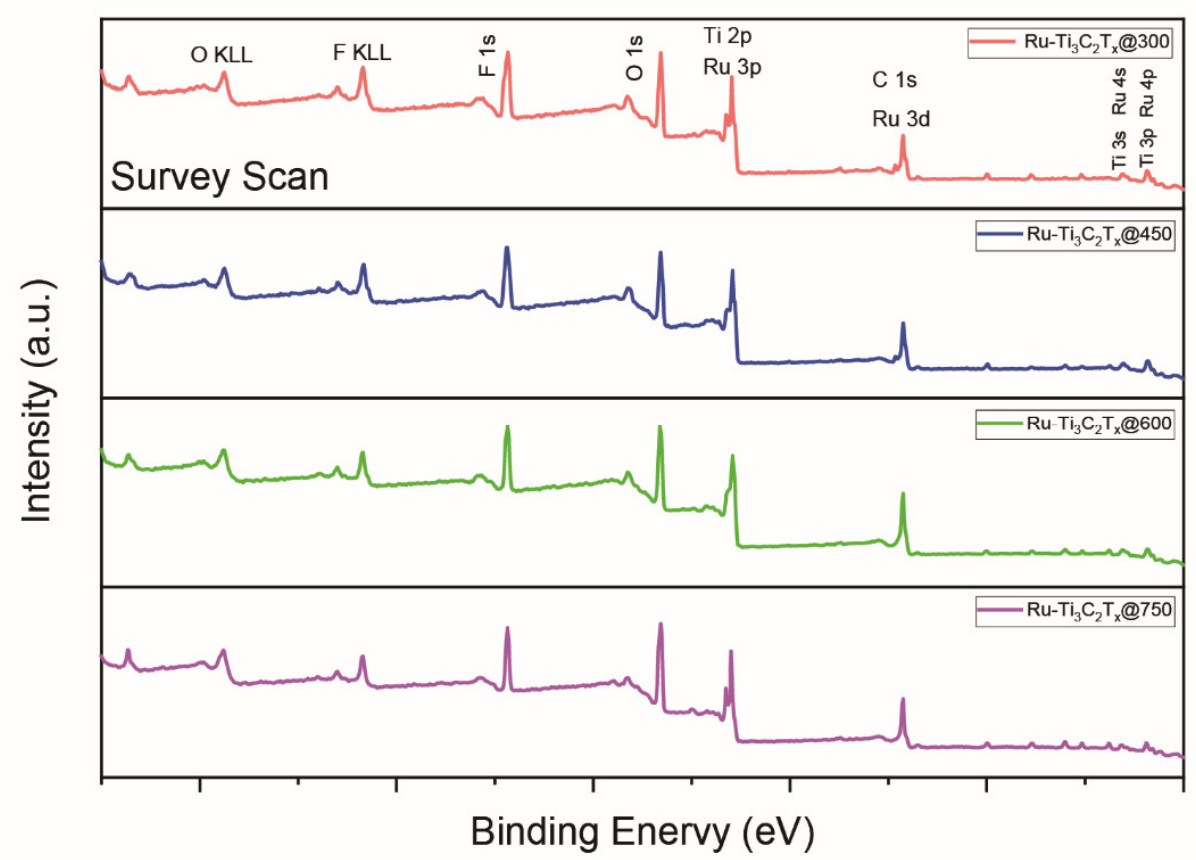

Figure S4. Survey scan XPS spectra of Ru-Ti $\mathrm{C}_{2} \mathrm{~T}_{\mathrm{x}} @ 300, \mathrm{Ru}-\mathrm{Ti}_{3} \mathrm{C}_{2} \mathrm{~T}_{\mathrm{x}} @ 450, \mathrm{Ru}-$ $\mathrm{Ti}_{3} \mathrm{C}_{2} \mathrm{~T}_{\mathrm{x}} @ 600$ and $\mathrm{Ru}-\mathrm{Ti}_{3} \mathrm{C}_{2} \mathrm{~T}_{\mathrm{x}} @ 750$. 


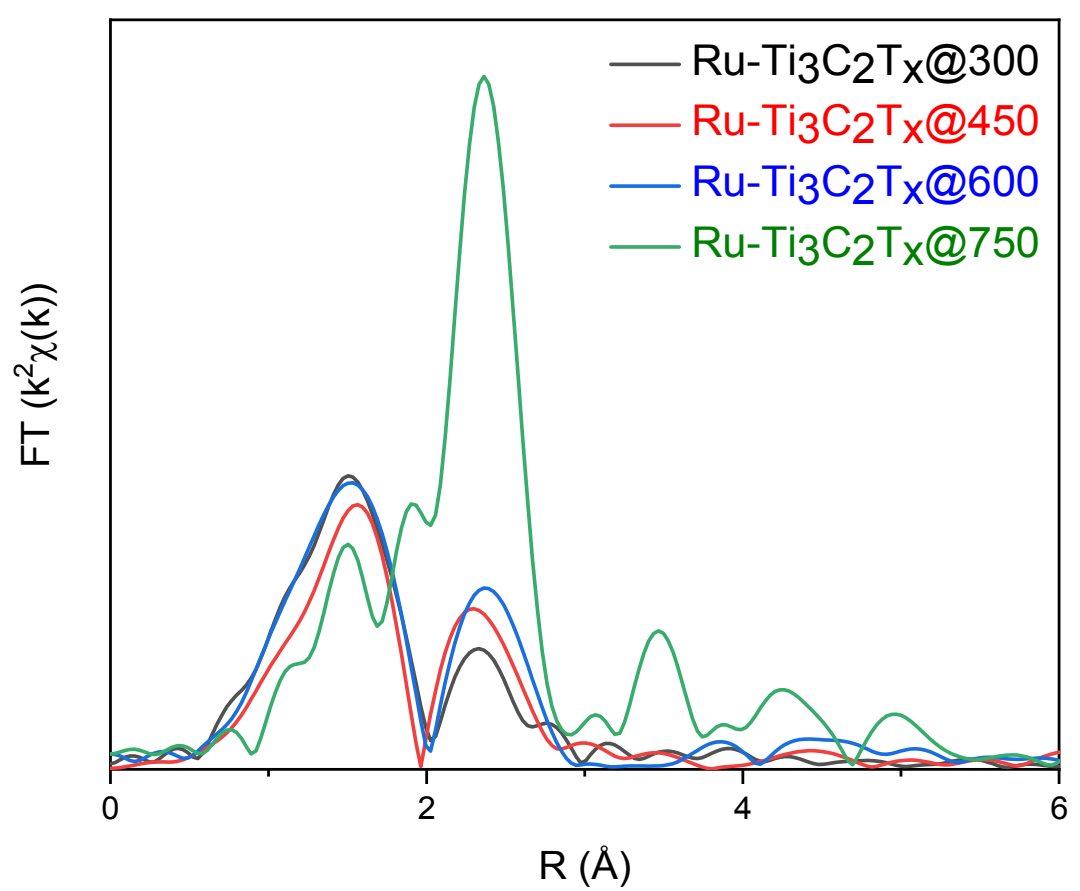

Figure S5. The FT-EXAFS spectra of Ru-Tii $\mathrm{C}_{2} \mathrm{~T}_{\mathrm{x}} @ 300, \mathrm{Ru}-\mathrm{Ti}_{3} \mathrm{C}_{2} \mathrm{~T}_{\mathrm{x}} @ 450, \mathrm{Ru}-$ $\mathrm{Ti}_{3} \mathrm{C}_{2} \mathrm{~T}_{\mathrm{x}} @ 600, \mathrm{Ru}-\mathrm{Ti}_{3} \mathrm{C}_{2} \mathrm{~T}_{\mathrm{x}} @ 750$.

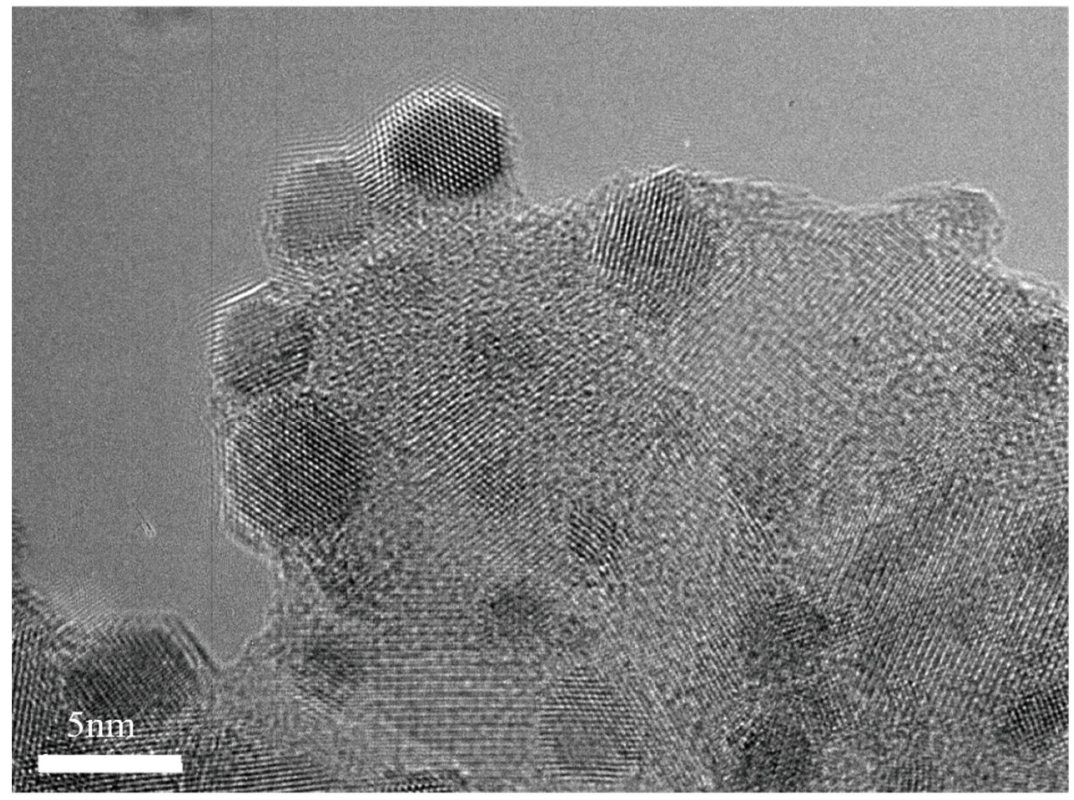

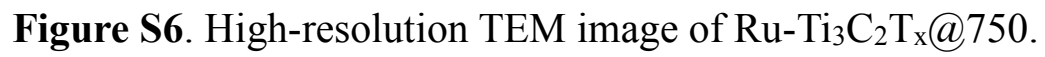




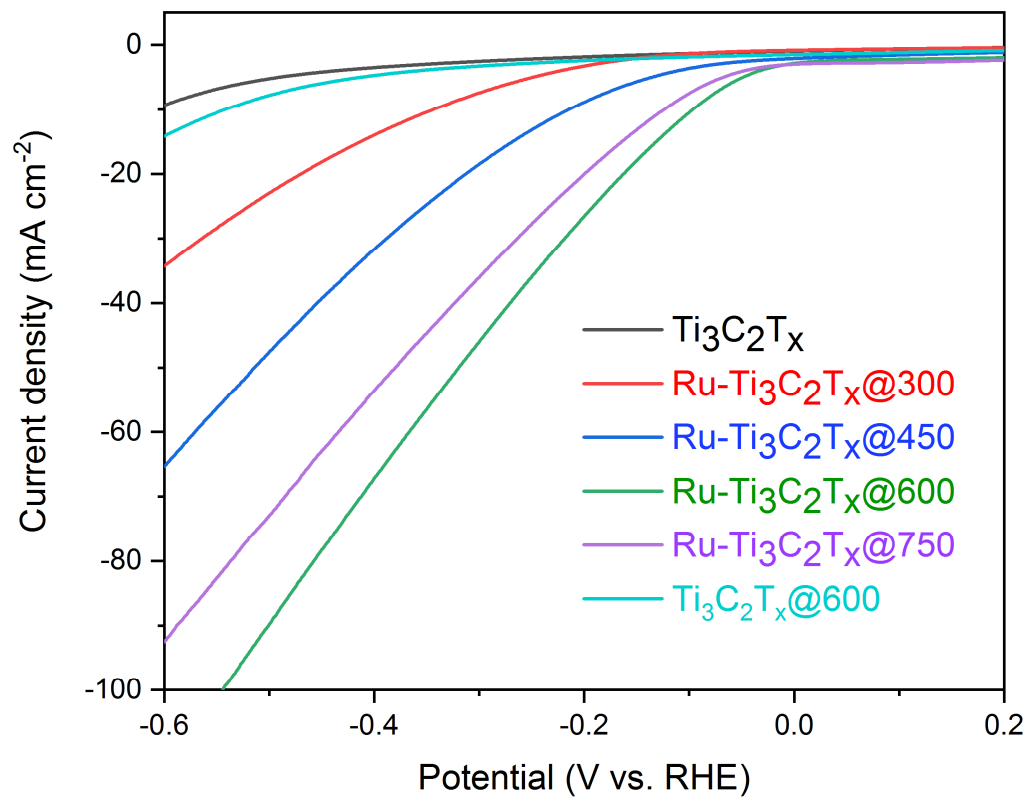

Figure S7. The LSV curves of the $\mathrm{Ti}_{3} \mathrm{C}_{2} \mathrm{~T}_{\mathrm{x}}$ and $\mathrm{Ru}-\mathrm{Ti}_{3} \mathrm{C}_{2} \mathrm{~T}_{\mathrm{x}} @ 300, \mathrm{Ru}-\mathrm{Ti}_{3} \mathrm{C}_{2} \mathrm{~T}_{\mathrm{x}} @ 450$, $\mathrm{Ru}-\mathrm{Ti}_{3} \mathrm{C}_{2} \mathrm{~T}_{\mathrm{x}} @ 600, \mathrm{Ru}-\mathrm{Ti}_{3} \mathrm{C}_{2} \mathrm{~T}_{\mathrm{x}} @ 750$ and $\mathrm{Ti}_{3} \mathrm{C}_{2} \mathrm{~T}_{\mathrm{x}} @ 600$ electrocatalyst recorded in 1 $\mathrm{M} \mathrm{KOH.}$

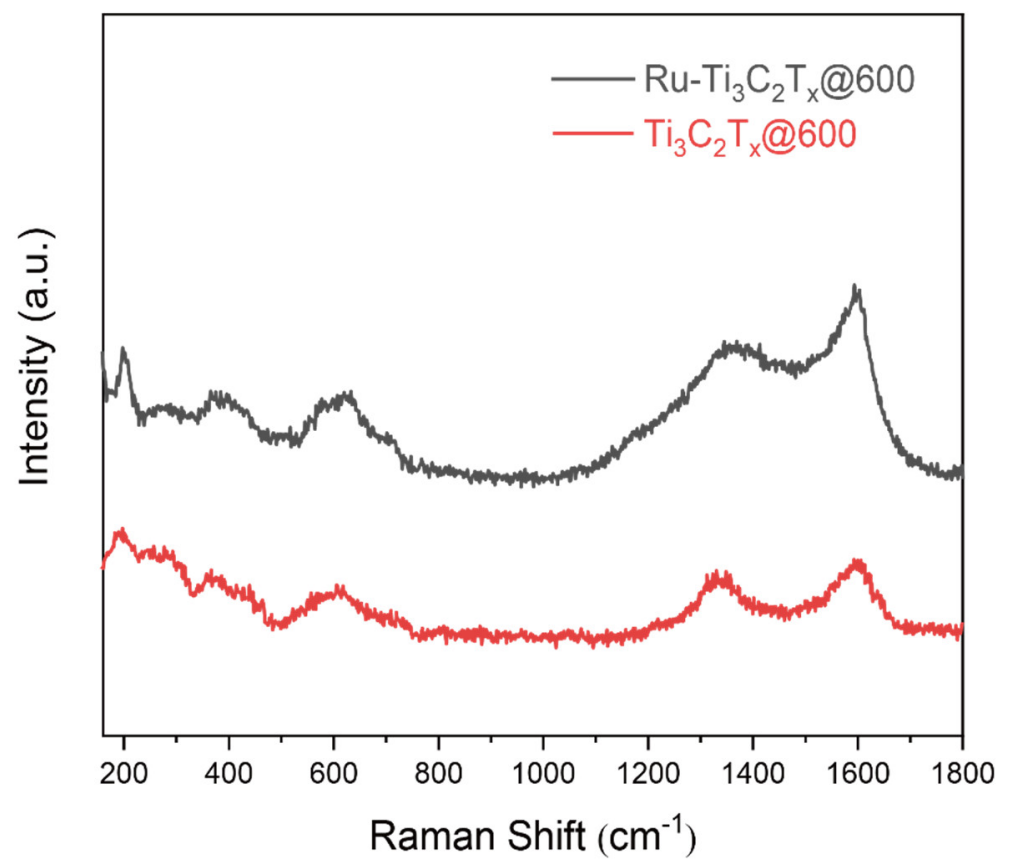

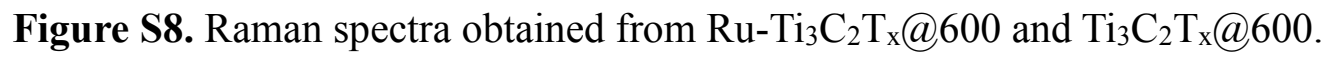



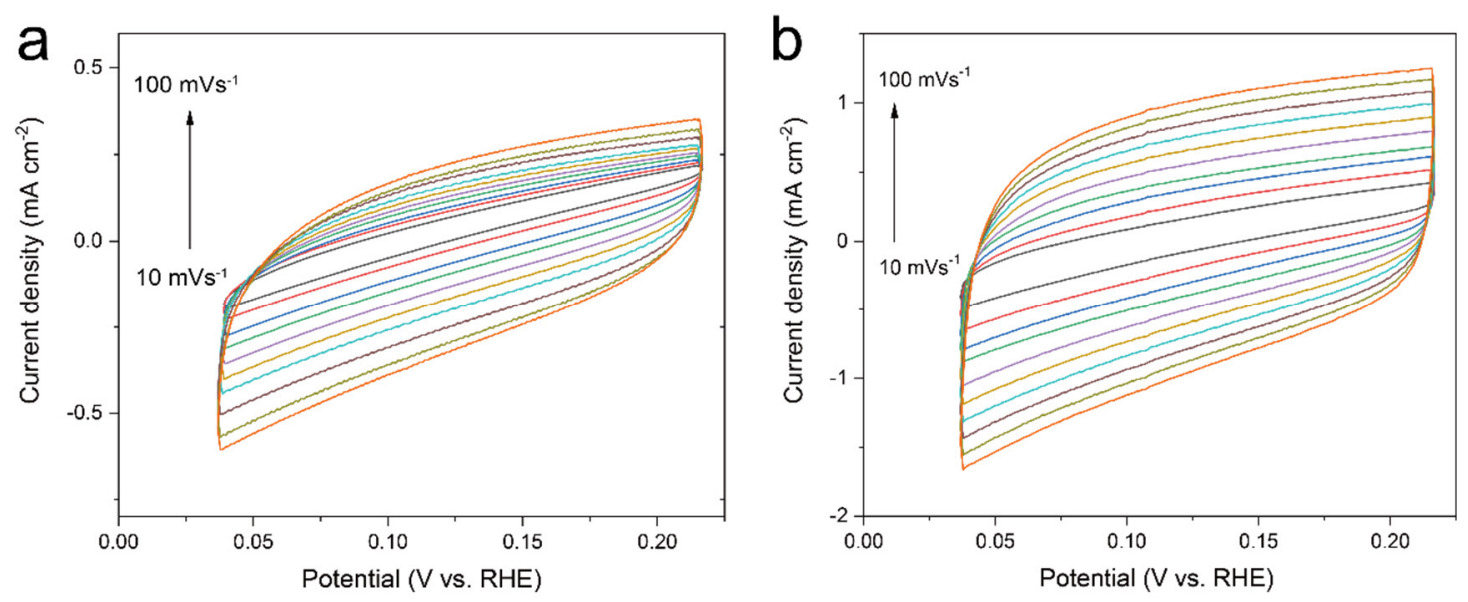

Figure S9. The CV curves of the $\mathrm{Ti}_{3} \mathrm{C}_{2} \mathrm{~T}_{\mathrm{x}}(\mathrm{a})$ and $\mathrm{Ru}-\mathrm{Ti}_{3} \mathrm{C}_{2} \mathrm{~T}_{\mathrm{x}} @ 600$ (b) electrocatalyst obtained at different scan rates in $1 \mathrm{M} \mathrm{KOH}$.

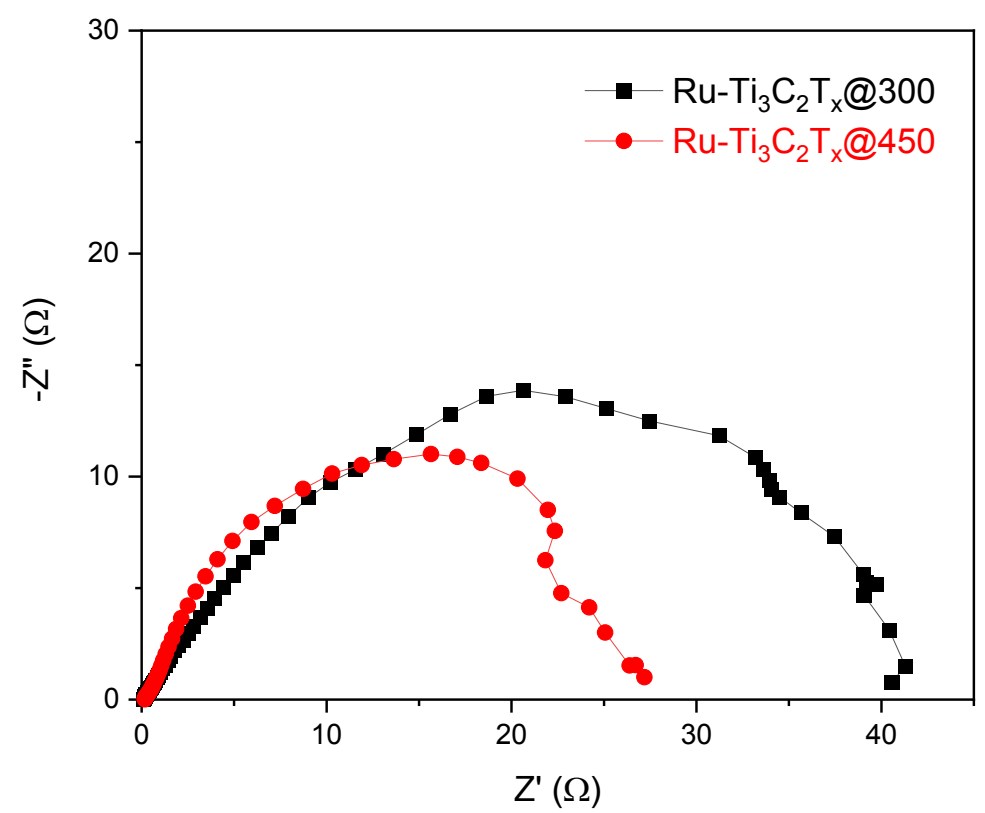

Figure S10. The EIS spectra of Ru-Ti ${ }_{3} \mathrm{C}_{2} \mathrm{~T}_{\mathrm{x}} @ 300$ and $\mathrm{Ru}-\mathrm{Ti}_{3} \mathrm{C}_{2} \mathrm{~T}_{\mathrm{x}} @ 450$. 

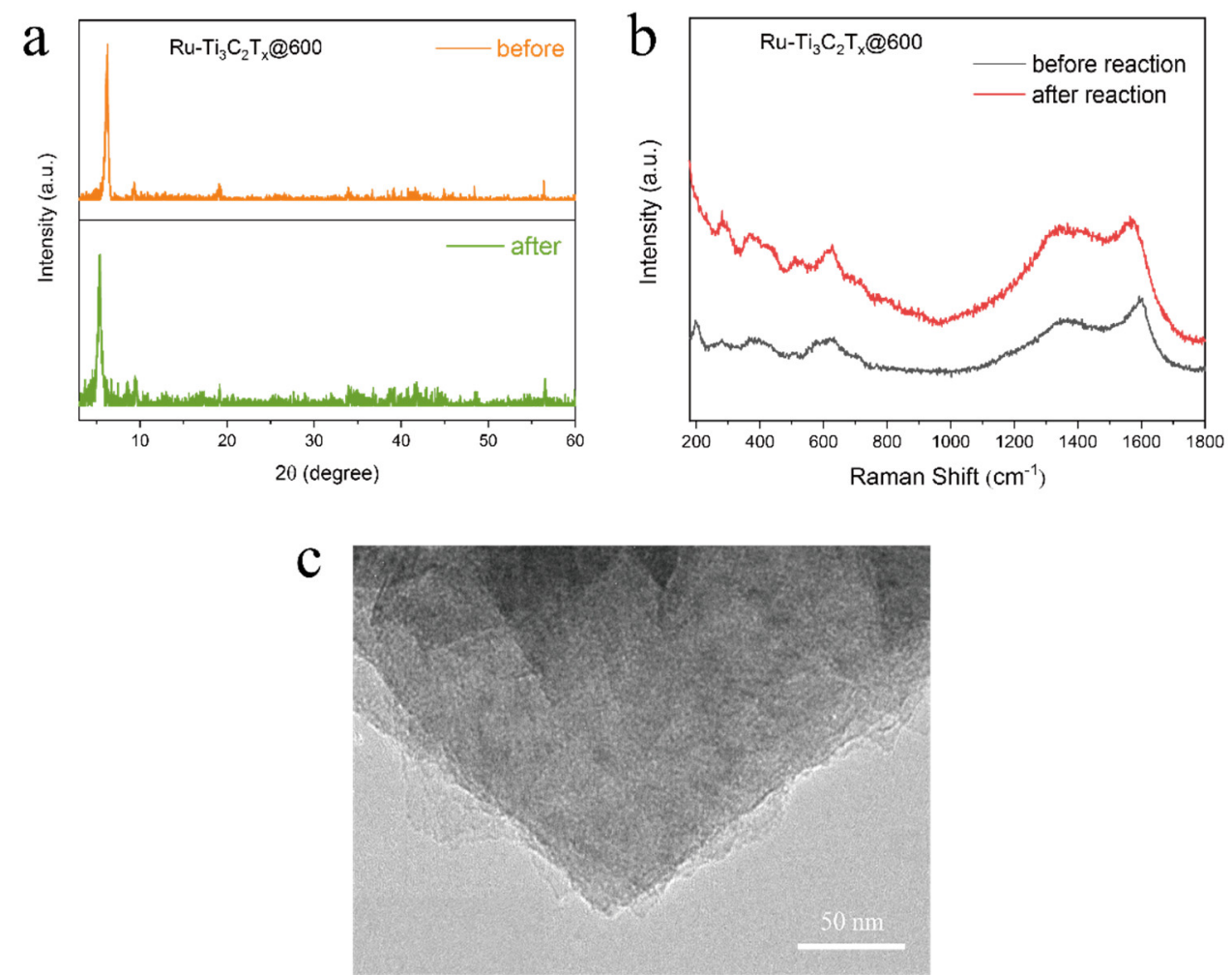

Figure S11. (a) XRD patterns and (b) Raman spectra of $\mathrm{Ru}-\mathrm{Ti}_{3} \mathrm{C}_{2} \mathrm{~T}_{\mathrm{x}} @ 600$ before and after electrocatalytic reaction. (c) TEM image of $\mathrm{Ru}^{-} \mathrm{Ti}_{3} \mathrm{C}_{2} \mathrm{~T}_{\mathrm{x}} @ 600$ after electrocatalytic reaction. 


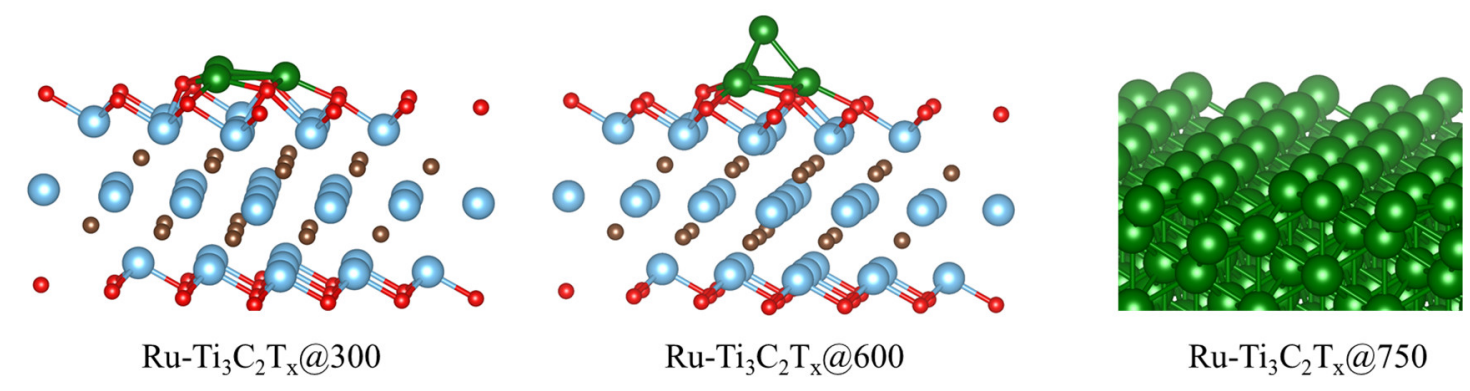

Figure S12. The atomic models of $\mathrm{Ru}^{-} \mathrm{Ti}_{3} \mathrm{C}_{2} \mathrm{~T}_{\mathrm{x}} @ 300, \mathrm{Ru}-\mathrm{Ti}_{3} \mathrm{C}_{2} \mathrm{~T}_{\mathrm{x}} @ 600$ and $\mathrm{Ru}-\mathrm{Ti}_{3} \mathrm{C}_{2} \mathrm{~T}_{\mathrm{x}} @ 750$ (light blue, brown, red and green balls represent Ti, C, O and Ru atoms, respectively).

As shown in the Figure S12, Ru clusters are loaded on the surface of MXene and bond with its surface $\mathrm{O}$ functional groups. The atomic model of $\mathrm{Ru}^{-\mathrm{Ti}_{3} \mathrm{C}_{2} \mathrm{~T}_{\mathrm{x}} @ 300 \text { has }}$ three $\mathrm{Ru}$ atoms, and each $\mathrm{Ru}$ atom bonds with two neighbouring $\mathrm{Ru}$ atoms. The atomic model of Ru- $\mathrm{Ti}_{3} \mathrm{C}_{2} \mathrm{~T}_{\mathrm{x}} @ 600$ has four Ru atoms in a tetrahedral configuration, and each $\mathrm{Ru}$ atom bonds with three neighbouring $\mathrm{Ru}$ atoms. We substitute a $\mathrm{Ru}(110)$ section model with a surface coordination number of 7 for the atomic model of $\mathrm{Ru}$ $\mathrm{Ti}_{3} \mathrm{C}_{2} \mathrm{~T}_{\mathrm{x}} @ 750$.

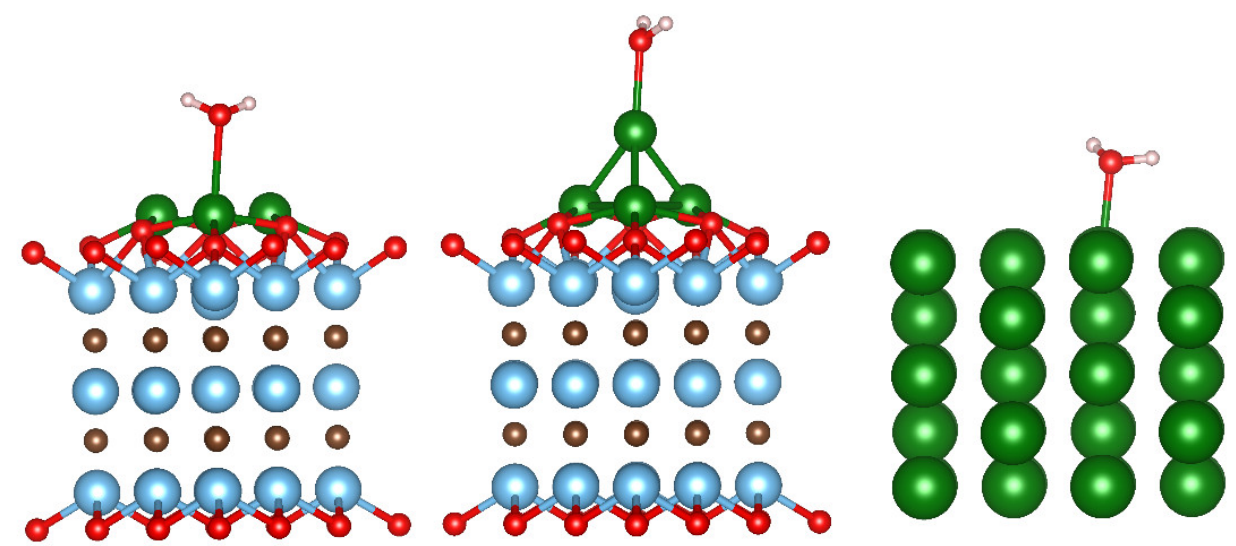

Figure S13. The atomic model of $\mathrm{H}_{2} \mathrm{O}$ adsorbed on the $\mathrm{Ru}^{-} \mathrm{Ti}_{3} \mathrm{C}_{2} \mathrm{~T}_{\mathrm{x}} @ 300$, $\mathrm{Ru}-\mathrm{Ti}_{3} \mathrm{C}_{2} \mathrm{~T}_{\mathrm{x}} @ 600$ and $\mathrm{Ru}-\mathrm{Ti}_{3} \mathrm{C}_{2} \mathrm{~T}_{\mathrm{x}} @ 750$ (light blue, brown, red, green and pink colored balls represent $\mathrm{Ti}, \mathrm{C}, \mathrm{O}, \mathrm{Ru}$ and $\mathrm{H}$ atoms, respectively). 
Table S1. EXAFS curve Fitting Parameters of the Ru K-edge.

\begin{tabular}{ccccccc}
\hline Sample & Path & $\mathrm{CN}$ & $\mathrm{R}(\AA)$ & $\sigma^{2}\left(10^{-3} \AA^{2}\right)$ & $\Delta \mathrm{E}_{0}(\mathrm{eV})$ & R-factor \\
\hline \multirow{2}{*}{$\mathrm{Ru}-\mathrm{Ti}_{3} \mathrm{C}_{2} \mathrm{~T}_{\mathrm{x}} @ 300$} & $\mathrm{Ru}-\mathrm{O}$ & 3.1 & 2.09 & 6.8 & 6.5 & \multirow{2}{*}{0.025} \\
\cline { 2 - 6 } & $\mathrm{Ru}-\mathrm{Ru}$ & 2.1 & 2.63 & 11.1 & -0.2 & \\
\hline $\mathrm{Ru}-\mathrm{Ti}_{3} \mathrm{C}_{2} \mathrm{~T}_{\mathrm{x}} @ 600$ & $\mathrm{Ru}-\mathrm{O}$ & 3.2 & 2.04 & 7.1 & 3.6 & \multirow{2}{*}{0.003} \\
\cline { 2 - 6 } & $\mathrm{Ru}-\mathrm{Ru}$ & 2.8 & 2.67 & 8.1 & 0.7 & \\
\hline $\mathrm{Ru}-\mathrm{Ti}_{3} \mathrm{C}_{2} \mathrm{~T}_{\mathrm{x}} @ 750$ & $\mathrm{Ru}-\mathrm{O}$ & 1.5 & 1.97 & 7.0 & -4.6 & \multirow{2}{*}{0.022} \\
\cline { 2 - 6 } & $\mathrm{Ru}-\mathrm{Ru}$ & 6.7 & 2.66 & 5.1 & -4.9 & \\
\hline
\end{tabular}

Table S2. Comparison table of electrocatalysts HER performance of Ru-based catalyst.

\begin{tabular}{|c|c|c|c|}
\hline Electrocatalysts & $\begin{array}{c}\text { Experimental } \\
\text { conditions } \\
\end{array}$ & $\begin{array}{c}\text { Overpotential@10 } \\
\mathrm{mA} / \mathrm{cm}^{2}(\mathrm{mV})\end{array}$ & Ref \\
\hline $\mathrm{Ru}-\mathrm{Ti}_{3} \mathrm{C}_{2} \mathrm{~T}_{\mathrm{x}} @ 600$ & $1.0 \mathrm{M} \mathrm{KOH}$ & 96 & This work \\
\hline $\begin{array}{c}\mathrm{Ru}(\mathrm{CF} @ \mathrm{Ru}-\mathrm{CoCH} \\
\mathrm{NWs})\end{array}$ & $1.0 \mathrm{M} \mathrm{KOH}$ & 66 & 5 \\
\hline $\mathrm{Ru} \mathrm{SAs}-\mathrm{Ni}_{2} \mathrm{P}$ & $0.5 \mathrm{M} \mathrm{H}_{2} \mathrm{SO}_{4}$ & 125 & 6 \\
\hline $\mathrm{Ru} / \mathrm{C}_{3} \mathrm{~N}_{4} / \mathrm{C}$ & $0.1 \mathrm{M} \mathrm{KOH}$ & 79 & 7 \\
\hline $\mathrm{Ru} / \mathrm{Co}_{\mathrm{x}} \mathrm{P} @ \mathrm{NC}$ & $0.5 \mathrm{M} \mathrm{H}_{2} \mathrm{SO}_{4}$ & 165 & 8 \\
\hline $\mathrm{Ru}-\mathrm{N}_{4}-\mathrm{P}$ & $0.5 \mathrm{M} \mathrm{H} 2 \mathrm{SO} 4$ & 78 & 9 \\
\hline $\mathrm{Ru} @ \mathrm{C}_{2} \mathrm{~N}$ & $0.5 \mathrm{M} \mathrm{H}_{2} \mathrm{SO}_{4}$ & 14 & 10 \\
\hline $\mathrm{Ru}-\mathrm{WSe}_{2}$ & $1.0 \mathrm{M} \mathrm{KOH}$ & 87 & 11 \\
\hline $\mathrm{Ru}_{1} \mathrm{CoP} / \mathrm{CDs}$ & $0.5 \mathrm{M} \mathrm{H}_{2} \mathrm{SO}_{4}$ & 49 & 12 \\
\hline $\mathrm{Ru} / \mathrm{Ni}_{2} \mathrm{P} @ \mathrm{NP}$ & $1.0 \mathrm{M} \mathrm{KOH}$ & 132 & 13 \\
\hline $\mathrm{Ru}-\mathrm{NiFe} \mathrm{LDH}-\mathrm{F} / \mathrm{NF}$ & $1.0 \mathrm{M} \mathrm{KOH}$ & 116 & 14 \\
\hline RuSAs@PN & $0.5 \mathrm{M} \mathrm{H}_{2} \mathrm{SO}_{4}$ & 24 & 15 \\
\hline RusA-N-S-Ti ${ }_{3} C_{2} T_{x}$ & $0.5 \mathrm{M} \mathrm{H}_{2} \mathrm{SO}_{4}$ & 76 & 16 \\
\hline
\end{tabular}




\section{References}

(1) Kresse, G.; Furthmuller, J. Efficiency of Ab-Initio Total Energy Calculations for Metals and Semiconductors Using a Plane-Wave Basis Set. Comput. Mater. Sci. 1996, $6,15-50$.

(2) Blöchl, P. E. Projector Augmented-Wave Method. Phy. Rev. B 1994, 50, 17953 17979.

(3) Perdew, J. P.; Burke, K.; Ernzerhof, M. Generalized Gradient Approximation Made Simple. Phys. Rev. Lett. 1996, 77, 3865-3868.

(4) Wang, V.; Xu, N.; Liu, J. C.; Tang, G.; Geng, W. T. VASPKIT: A User-Friendly Interface Facilitating High-Throughput Computing and Analysis Using VASP Code. Comput. Phys. Commun. 2021, 267, 108033.

(5) Li, J.; Zhou, Q.; Shen, Z.; Li, S.; Pu, J.; Zhong, C.; Cao, M.; Jin, X.; Zhang, H.; Wang, Y.; Ma, H. Synergistic Effect of Ultrafine Nano-Ru Decorated Cobalt Carbonate Hydroxides Nanowires for Accelerated Alkaline Hydrogen Evolution Reaction. Electrochim. Acta. 2020, 331, 135367.

(6) Wu, K.; Sun, K.; Liu, S.; Cheong, W. C.; Chen, Z.; Zhang, C.; Pan, Y.; Cheng, Y.; Zhuang, Z.; Wei, X.; Wang, Y.; Zheng, L.; Zhang, Q.; Wang, D.; Peng, Q.; Chen, C.; Li, Y. Atomically Dispersed Ni-Ru-P Interface Sites for High-Efficiency pHUniversal Electrocatalysis of Hydrogen Evolution. Nano Energy. 2021, 80, 105467.

(7) Zheng, Y.; Jiao, Y.; Zhu, Y.; Li, L.; Han, Y.; Chen, Y.; Jaroniec, M.; Qiao, S. Z. High Electrocatalytic Hydrogen Evolution Activity of an Anomalous Ruthenium Catalyst. J. Am. Chem. Soc. 2016, 138, 16174-16181.

(8) Si, C. D.; Wu, Z. X.; Wang, J.; Lu, Z. H.; Xu, X. F.; Li, J. S. Enhanced the Hydrogen Evolution Performance by Ruthenium Nanoparticles Doped into Cobalt Phosphide Nanocages. ACS Sustain. Chem. Eng. 2019, 7, 9737-9742.

(9) Wu, C.; Ding, S.; Liu, D.; Li, D.; Chen, S.; Wang, H.; Qi, Z.; Ge, B.; Song, L. A Unique Ru-N4-P Coordinated Structure Synergistically Waking Up the Nonmetal P Active Site for Hydrogen Production. Research. 2020, 2020. 1.

(10) Mahmood, J.; Li, F.; Jung, S. M.; Okyay, M. S.; Ahmad, I.; Kim, S.; Park, N.; Jeong, H.Y.; Baek, J. An Efficient and pH-Universal Ruthenium-Based Catalyst for 
the Hydrogen Evolution Reaction. Nat. Nanotechnol. 2017, 12, 441-446.

(11) Zhao, Y.; Mao, G.; Huang, C.; Cai, P.; Cheng, G.; Luo, W. Decorating WSe 2 Nanosheets with Ultrafine Ru Nanoparticles for Boosting Electrocatalytic Hydrogen Evolution in Alkaline Electrolytes. Inorg. Chem. Front., 2019, 6, 1382-1387.

(12) Song, H.; Wu, M.; Tang, Z.; Tse, J. S.; Yang, B.; Lu, S. Single Atom RutheniumDoped CoP/CDs Nanosheets via Splicing of Carbon-Dots for Robust Hydrogen Production. Angew. Chem. Int. Ed. 2021, 60, 7234-7244.

(13) Chi, J. Q.; Zhang, X. Y.; Ma, X.; Dong, B.; Zhang, J. Q.; Guo, B. Y.; Yang, M.; Wang, L.; Chai, Y. M.; Liu, C. Interface Charge Engineering of Ultrafine Ru/Ni2P Nanoparticles Encapsulated in N,P-Codoped Hollow Carbon Nanospheres for Efficient Hydrogen Evolution. ACS Sustain. Chem. Eng. 2019, 7, 17714-17722. (14) Wang, Y.; Zheng, P.; Li, M.; Li, Y.; Zhang, X.; Chen, J.; Fang, X.; Liu, Y.; Yuan, X.; Dai, X.; Wang, H. Interfacial Synergy between Dispersed Ru Sub-Nanoclusters and Porous NiFe Layered Double Hydroxide on Accelerated overall Water Splitting by Intermediate Modulation. Nanoscale, 2020, 12, 9669-9679.

(15) Yang, J.; Chen, B.; Liu, X.; Liu, W.; Li, Z.; Dong, J.; Chen, W.; Yan, W.; Yao, T.; Duan, X.; Wu, Y.; Li, Y. Efficient and Robust Hydrogen Evolution: Phosphorus Nitride Imide Nanotubes as Supports for Anchoring Single Ruthenium Sites. Angew. Chem. Int. Ed. 2018, 130, 9639-9644.

(16) Ramalingam, V.; Varadhan, P.; Fu, H. C.; Kim, H.; Zhang, D.; Chen, S.; Song, L.; Ma, D.; Wang, Y.; Alshareef, H. N.; He, J. H. Heteroatom - Mediated Interactions between Ruthenium Single Atoms and an MXene Support for Efficient Hydrogen Evolution. Adv. Mater. 2019, 31, 1903841. 